\title{
Discovering Inhibitors of Tyrosinase Enzyme from Zingiberaceae for Depigmentation Agents
}

\author{
Karina Muthia $^{1}$, Fride Rindu Alami ${ }^{1}$, Nyi Mekar Saptarini ${ }^{1,2}$, Jutti Levita ${ }^{1 *}$ \\ ${ }^{I}$ Department of Pharmaceutical Analysis and Medicinal Chemistry, Faculty of Pharmacy, Universitas Padjadjaran \\ Jl. Raya Bandung-Sumedang km.21 Jatinangor, West Java, Indonesia 45363. \\ ${ }^{2}$ School of Pharmacy, Bandung Institute of Technology, Labtek VII, Ganesha 10 Bandung 40132, Indonesia.
}

Received: 30 September 2014 / Accepted: 30 November 2014

\begin{abstract}
:
Tyrosinase enzyme, which has two copper ions in its catalytic site, involved in skin pigmentation by catalyzing three oxidation reactions on melanogenesis, that are conversion of L-tirosine to L-DOPA, L-DOPA to dopaquinone, and 5,6-dihydroxyindole to 5,6-indolequinone. An inhibition of melanogenesis was proven in vitro by bioactive compounds of Zingiberaceae plants, which are ethyl p-metoxycinnamate, galangin $\left(\mathrm{IC}_{50} 10 \mu \mathrm{M}\right)$, 6-gingerol $\left(\mathrm{IC}_{50} 25-100 \mu \mathrm{M}\right)$, 4-hydroxypanduratin-A ( $\left.\mathrm{IC}_{50} 23.2 \mu \mathrm{M}\right)$, isopanduratin-A ( $\left.\mathrm{IC}_{50} 10.6 \mu \mathrm{M}\right)$, kaempferol $\left(\mathrm{IC}_{50} 0.23 \mu \mathrm{M}\right)$, and kaempferida. In this paper we studied the interaction of these compounds with tyrosinase enzyme using AutoDock Vina. The interactions were then compared to arbutin (hydroquinone- $\beta$-D-glucoside), kojic acid, and hydroquinone, which have been well known as depigmentation agents in cosmetics. All bioactive compounds of Zingiberaceae plants were able to interact with tyrosinase. Compared to others, kaempferol showed the lowest inhibition constant value $(\mathrm{Ki} 2.7 \mu \mathrm{M})$ and two metal interactions with both copper ions, Cu501 and $\mathrm{Cu} 502$, which means that this compound was predicted as the strongest inhibitor of tyrosinase enzyme. Kaempferol interacted with tyrosinase by blocking the entrance of the enzyme's catalytic site, therefore it will prevent the substrate to react with the enzyme. It can be concluded that bioactive compounds of Zingiberaceae can be developed as an inhibitors of tyrosinase.
\end{abstract}

Key words: Arbutin, gingerol, kaempferol, kojic acid, melanogenesis, molecular docking, Zingiberaceae

\section{Introduction}

Tyrosinase enzyme, which has two copper ions in its catalytic site, involved in skin pigmentation by catalyzing three oxidation reactions on melanogenesis, that are: (1) conversion of L-tyrosine to L-DOPA, (2) LDOPA to dopaquinone, and (3) 5,6-dihydroxyindole to 5,6-indolequinone. Tyrosinases catalyze the oxidations of both monophenols (cresolase or monophenolase activity) and $\mathrm{O}$-diphenols (catecholase or diphenolase activity) into reactive $\mathrm{O}$-quinones. The term tyrosinase refers to its typical substrate, tyrosine [1], therefore by inhibiting this substrate, melanogenesis or furthermore, skin pigmentation, could be prevented.

Tyrosinase inhibitors or competitive antagonists of tyrosine are commonly used in dermatological treatments as depigmentation agents. There is plenty of tyrosinase inhibitors derived from either plants or synthetic sources, which have been investigated. An inhibition of melanogenesis was proven in vitro by bioactive compounds of Zingiberaceae plants, which are ethyl p-metoxycinnamate (EPMC), galangin $\left(\mathrm{IC}_{50}=10\right.$ $\mu \mathrm{M})$, 6-gingerol $\left(\mathrm{IC}_{50}=25-100 \mu \mathrm{M}\right)$, 4-hydroxypanduratin- $\mathrm{A}\left(\mathrm{IC}_{50}=23.2 \mu \mathrm{M}\right)$, isopanduratin- $\mathrm{A}\left(\mathrm{IC}_{50}=\right.$ $10.6 \mu \mathrm{M})$, kaempferol $\left(\mathrm{IC}_{50}=0.23 \mu \mathrm{M}\right)$, and kaempferida $[2,3,4]$.

The mechanism of action of tyrosinase inhibitors can be accomplished by one of the following: (a) Reducing agent such as ascorbic acid causes chemical reduction of dopaquinone, and reduces O-dopaquinone to L-DOPA, thus avoiding formation of dopachrome and melanin; (b) O-Dopaquinone scavenger such as most thio-containing compounds could react with dopaquinone, to form colorless products. Then the melanogenesis is slowed down, until all the scavengers are consumed; (c) Some phenolic compounds act as alternative tyrosinase substrates, their quinoid reaction products absorb in a spectral range different from that of dopachrome. When these phenolics exhibit a good affinity for tyrosinase, dopachrome formation is prevented, hence they could be regarded as tyrosinase inhibitors; (d) Nonspecific tyrosinase inactivators such as acids or bases, which non-specifically denature the enzyme and inhibit its activity. Those acids or bases are sometimes mistakenly regarded as tyrosinase inhibitors [4]. Actually, the specific tyrosinase inhibitors should be catalyzed by tyrosinase and form covalent bond with the enzyme, thus irreversibly inactivating the enzyme during catalytic reaction [5].

In this paper, we studied the binding modes of galangin, EPMC, kaempferol, 6-gingerol, 4-hydroxypanduratin-A, isopanduratin-A, and kaempferida, bioactive compounds of Zingiberaceae, with tyrosinase enzyme using AutoDock Vina for discovering depigmentation agents from natural sources.

\footnotetext{
*Corresponding author: Jutti Levita,
}

E-mail: jutti.levita@unpad.ac.id 


\section{Experimental}

Materials

Hardwares: Windows $7^{\mathrm{TM}}$ Ultimate personal computer with Pentium Dual Core $2.10 \mathrm{GHz}$ processor, 32 bit 232 GB hard disk, RAM 2.0 GB.

\section{Softwares}

(1) ChemBio 3D 12.0.2 with free trial serial number: 186-410320-7811 (downloaded from http://www.cambridgesoft.com); (2) OpenBabel v2.1.1 (downloaded from http://openbabel.org/); (3) Portable HyperChem Release 8.07 verification code : 0-28331 (http://www.hyper.com); (4) SwissPDBViewer v.4.01 (GlaxoSmithKline R\&D, downloaded from http://www. expasy.org); (5) AutoDock Vina (Molecular Graphics Laboratory, The Scripps Research Institute downloaded from http://mgltools. scripps.edu); (6) Ligand Explorer Viewer v.3.8 (Research Collaboratory for Structural Bioinformatics embedded at http://www.pdb.org/pdb/ explore); (7) Q-SiteFinder an online freeware that is used to predict binding sites and calculate the volume of protein and binding sites (http://www.bioinformatics. leeds.ac.uk/ qsitefinder/).

\section{Data Preparation}

The $\mathrm{x}$-ray crystallographic 3D structures of tyrosinase enzyme (PDB ID 3NQ1) crystallized by Sendovski, et. al., (2010) resolution $2.3 \AA$ was downloaded from online Protein Data Bank (http://www.rcsb.org/pdb/).

Tyrosinase is a homodimer enzyme. The monomer was separated and repaired using SwissPDBViewer. Kojic acid that was co-crystallized in the enzyme was extracted and saved to be used for validation.

\section{Molecular Modeling}

Two Dimentional and Three Dimentional structures of EPMC, galangin, 6-gingerol, 4-hydroxypanduratin-A, isopanduratin-A, kaempferol, and kaempferida were built using ChemBio 3D 12.0.2. Energy minimization to each molecule was carried out using AM1 semiempirical method with Polak-Ribiere (conjugate-gradient) algorithm, RMS gradient of $0.1 \mathrm{kcal} / \AA \hat{\mathrm{A}} \mathrm{mol}$ or 375 maximum cycles in vacuo. Molecular surfaces of all compounds by means their potential electrostatic maps and their QSAR properties were also computed using Portable HyperChem Release 8.07. Hydrogen were added to tyrosinase enzyme PDB crystal structures. Binding sites prediction was performed by submitting the macromolecule to http://www.bioinformatics.leeds. ac.uk/qsitefinder/ to calculate the most likely sites for the ligand-enzyme interactions based on the lowest energy of the sites.

\section{Analysis of Binding Sites Residues}

The x-ray crystallographic 3D structures of tyrosinase enzyme (PDB ID 3NQ1) complexed with kojic acid, a well-known inhibitor, was studied to obtain information about the binding modes, which in this case referred to the amino acid residues in the binding site, the hydrogen bonds, the hydrophobic interactions, as well as the metal interaction. Software used in this step was Ligand Explorer Viewer v.3.8 that is embedded at http://www.pdb.org/pdb/explore.

\section{Molecular Docking}

The prediction of interaction of EPMC, galangin, 6gingerol, 4-hydroxypanduratin-A, isopanduratin-A, kaempferol, and kaempferida with tyrosinase enzyme is the main challenge to understand their depigmentation property as already showed by in vitro study. The goal is to take the 3D coordinates of the enzyme and its complexed ligand (kojic acid) which has been known as inhibitor to tyrosinase, and to simulate the docking of our compounds into the site in which kojic acid was cocrystallized. The interactions between kojic acid and amino acid residues in tyrosinase binding site were analyzed and compared with those of EPMC, galangin, 6-gingerol, 4-hydroxypanduratin-A, isopanduratin-A, kaempferol, and kaempferida.

\section{Results and Discussion}

The chemical structures of the compounds are showed in Figure 1. Compounds used in this project are EPMC, galangin, 6-gingerol, isopanduratin-A, 4-hydroxypanduratin-A, kaempferol, and kaempferida, while the standards are arbutin, kojic acid, and hydroquinone.

QSAR properties of the compounds and potential electrostatic maps of the most hydrophobic and hydrophilic compounds were computed using Portable HyperChem Release 8.07. The results were showed in Table 1 and Figure 2.

Isopanduratin-A is the most hydrophobic molecule with Log P 6.18 due to its aromatic rings, alkyl, and acetyl moieties, while kojic acid is the most hydrophilic of all, $\log \mathrm{P}-0.05$, as it has two $\mathrm{HB}$ donors and four $\mathrm{HB}$ acceptors (Table 1).

Potential electrostatic maps (Figure 2) showed that in isopanduratin-A molecule the electropositive region are distributed evenly as showed by the green color, while in kojic acid molecule there are four magenta clouds, indicate the electronegative area, besides the green electropositive parts, therefore it confirms that kojic acid is a polar molecule.

Two copper (II) ions, serving as the major cofactors in the catalytic site of tyrosinase, are covalently bound by six conserved histidine residues (His42, His60, His69, His204, His208, and His231). However, determination of structures under different conditions shows varying occupancies and positions of the copper ions, which indicate that there is a pathway by which copper is accumulated or lost by the enzyme. Inhibitor kojic acid co-crystallized in the enzyme, revealed additional 
residues involved in the positioning of substrates in the active site [6].<smiles>CCOC(=O)/C=C/c1ccc(OC)cc1</smiles>

EPMC<smiles>CCCCC[C@H](O)CC(=O)CCc1ccc(O)c(OC)c1</smiles>

6-gingerol<smiles>CC(C)=CCc1c(C)ccc(-c2ccccc2)c1C(=O)c1c(O)cc(O)cc1O</smiles>

Isopanduratin-A<smiles>Oc1ccc(O)cc1</smiles>

Hydroquinone

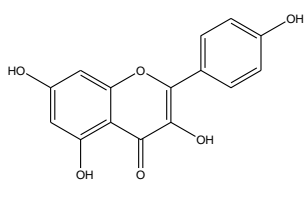

Kaempferol

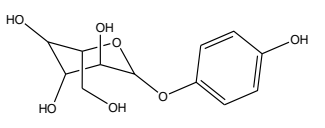

Arbutin
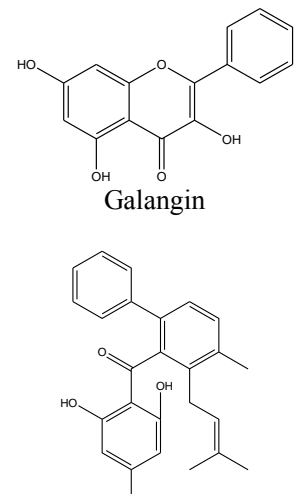

4-hydroxypanduratin A

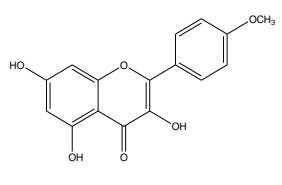

Kaempferida

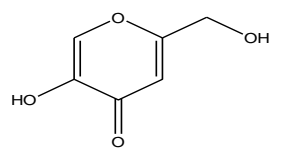

Kojic acid
Figure 1. Chemical structure of the compounds.

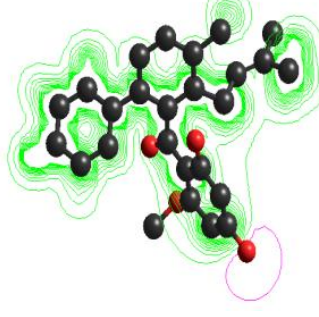

Isopanduratin-A

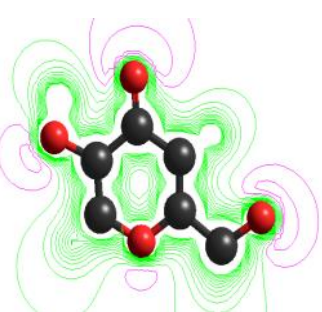

Kojic acid
Figure 2. Potential electrostatic map of isopanduratin-A and kojic acid.

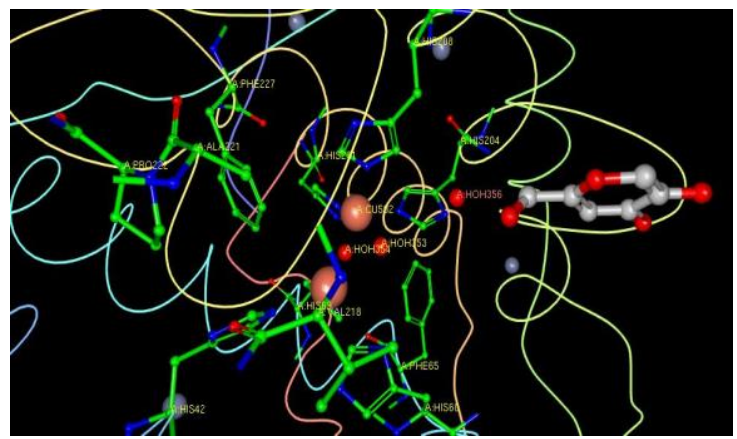

Figure 3. Catalytic pocket of tyrosinase enzyme (PDB ID 3NQ1) with its copper ions, amino acid residues and kojic acid.
Table 1. QSAR properties.

\begin{tabular}{lrrr}
\hline Compounds & cLog P & \multicolumn{1}{c}{$\begin{array}{c}\text { Volume } \\
\left(\AA^{3}\right)\end{array}$} & $\begin{array}{c}\text { Mass } \\
(\mathrm{amu})\end{array}$ \\
\hline EPMC & 6.18 & 795.44 & 300.27 \\
Galangin & 2.37 & 718.33 & 270.24 \\
6-gingerol & 3.78 & 974.20 & 294.39 \\
4-hydroxypanduratin- $\mathrm{A}$ & 6.12 & 1131.60 & 388.46 \\
Isopanduratin-A & $\mathbf{6 . 1 5}$ & 1212.51 & 402.49 \\
Kaempferol & 2.09 & 739.36 & 286.24 \\
Kaempferida & 2.12 & 795.44 & 300.27 \\
Arbutin & $\mathbf{0 . 0 1}$ & 721.37 & 272.25 \\
Kojic acid & -0.05 & 423.08 & 142.11 \\
Hydroquinone & 1.48 & 374.02 & 110.11 \\
\hline
\end{tabular}

Molecular docking of EPMC, galangin, 6-gingerol, 4hydroxypanduratin-A, isopanduratin-A, kaempferol, and kaempferida into the site in which kojic acid was cocrystallized is showed in Table 2 .

Table 2. Docking and scoring of compounds to tyrosinase enzyme.

\begin{tabular}{|c|c|c|c|}
\hline Compounds & $\begin{array}{l}\text { Scoring } \\
(\mathrm{kcal} / \mathrm{mol})\end{array}$ & $\begin{array}{l}\mathrm{Ki} \\
(\mu \mathrm{M})\end{array}$ & HB \\
\hline Isopanduratin-A & -7.2 & 5.3 & $\begin{array}{c}\mathrm{O}(\mathrm{C}=\mathrm{O}) \leftarrow \mathrm{Gly} 216 \\
(1.927 \dot{\mathrm{A}})\end{array}$ \\
\hline 4-hydroxypanduratin-A & -7.1 & 6.3 & $\begin{array}{c}\mathrm{O}(\mathrm{C}=\mathrm{O}) \leftarrow \mathrm{Gly} 216 \\
(1.945 \dot{\mathrm{A}})\end{array}$ \\
\hline Kaempferida & -7.6 & 2.7 & - \\
\hline EPMS & -5.7 & 66.6 & - \\
\hline 6-gingerol & -5.4 & 110.5 & - \\
\hline Galangin & -7.1 & 6.27 & $\begin{array}{c}\text { H-gal } \rightarrow \text { O-Gly } 216 \\
(1,754 \AA)\end{array}$ \\
\hline Kaempferol & -7.6 & 2.7 & - \\
\hline Arbutin & -6.5 & 17.3 & $\begin{array}{l}\mathrm{O}(\mathrm{OH}) \leftarrow \mathrm{Arb} \\
(2.075 \mathrm{~A})\end{array}$ \\
\hline Kojic acid & -5.6 & 78.9 & - \\
\hline Hydroquinone & -5.4 & 110.5 & $\begin{array}{c}\mathrm{O}(\mathrm{C}=\mathrm{O}) \leftarrow \mathrm{Met} 215 \\
(1.885 \mathrm{~A})\end{array}$ \\
\hline
\end{tabular}

Compared to others, kaempferol showed the lowest inhibition constant value $(\mathrm{Ki} 2.7 \mu \mathrm{M})$ and two metal interactions with both copper ions (Figure 4), which means that this compound was predicted as the strongest inhibitor of tyrosinase enzyme. Kaempferol interacted with tyrosinase by blocking the entrance of the enzyme's catalytic site, therefore it will prevent the substrate to react with the enzyme. 


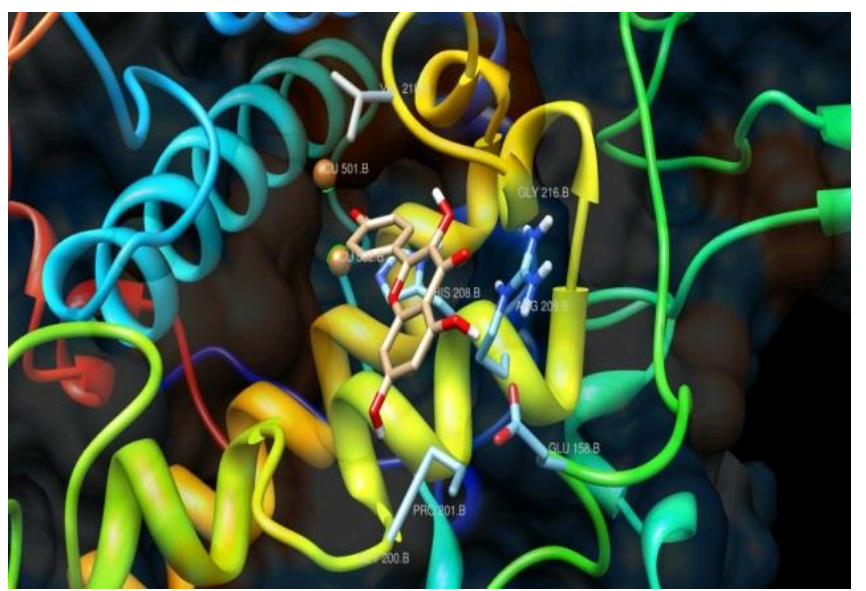

Figure 4. Binding site of kaempferol in tyrosinase.

\section{Conclusions}

It can be concluded that bioactive compounds of Zingiberaceae can be developed as an inhibitors of tyrosinase.

\section{Acknowledgement}

The authors would like to thank the Directorate General of Higher Education for the PKM grant to fund this project.

\section{References}

[1] T.S. Chang, Int. J. Mol. Sci., 10,2009, 2440-2475.

[2] J.H. Yoon, J.S. Shim, Y. Cho, N.I. Baek, C.W. Lee, H.S. Kim, and J.K. Hwang, Biol. Pharm. Bull., 30, 2007, 21412145.

[3] I. Kubo, I. Kinst-Hori, S.K. Chaudhuri, Y. Kubo, Y. Sánchez, and T. Ogura, Bioorg. Med. Chem., 8, 2000, 1749-1755.

[4] H. Matsuda, S. Nakashima, Y. Oda, S. Nakamura, and M. Yoshikawa, Bioorg. Med. Chem., 15, 2009, 6048-6053.

[5] T.M. Chang, J. Biocatal. Biotransformation, 2, 2012, 1-2.

[6] M. Sendovski, M. Kanteev, V.S. Ben-Yosef, N. Adir, and A. Fishman, First structures of an active bacterial tyrosinase reveal copper plasticity, J. Mol. Biol., 405(1), 2010, 227-237. 